NBER WORKING PAPER SERIES

\title{
SOCIAL VALUE OF PUBLIC INFORMATION: MORRIS AND SHIN (2002) IS ACTUALLY \\ PRO TRANSPARENCY, NOT CON
}

\author{
Lars E.O. Svensson \\ Working Paper 11537 \\ http://www.nber.org/papers/w11537
NATIONAL BUREAU OF ECONOMIC RESEARCH
1050 Massachusetts Avenue
Cambridge, MA 02138
August 2005

Comments by Alan Blinder, Frank Heinemann, Hyun Shin, and Christopher Sims are gratefully acknowledged. I thank Kathleen Hurley for editorial and secretarial assistance. Expressed views and any remaining errors are my own responsibility. The views expressed herein are those of the author(s) and do not necessarily reflect the views of the National Bureau of Economic Research.

(C2005 by Lars E.O. Svensson. All rights reserved. Short sections of text, not to exceed two paragraphs, may be quoted without explicit permission provided that full credit, including () notice, is given to the source. 
Social Value of Public Information: Morris and Shin (2002) Is Actually Pro Transparency, Not Con

Lars E.O. Svensson

NBER Working Paper No. 11537

August 2005

JEL No. D82, D83, E52, E58

\title{
ABSTRACT
}

The main result of Morris and Shin (2002) (restated in papers by Amato, Morris, and Shin (2002) and Amato and Shin (2003) and commented upon by Economist (2004)) has been presented and interpreted as an anti-transparency result: more public information can be bad. However, some scrutiny of the result shows that it is actually pro transparency: except in very special circumstances, more public information is good. Furthermore, for a conservative benchmark of equal precision in public and private information, social welfare is higher than in a situation without public information.

\author{
Lars E.O. Svensson \\ Department of Economics \\ Fisher Hall \\ Princeton University \\ Princeton, NJ 08544-1021 \\ and NBER \\ svensson@princeton.edu
}


The main result of Morris and Shin [8] has been presented and interpreted as an anti-transparency result: more public information can be bad for social welfare. This result has received considerable attention. It is emphasized in Amato, Morris, and Shin [1]; Amato and Shin [2]; and Economist [6]. It has been interpreted as suggesting that central banks should exercise caution in how much information they reveal. "It's not always good to talk" is the headline of Economist [6]. However, some scrutiny of the result shows that it is actually pro transparency: except in very special circumstances, more public information is good (see also Svensson [11]). Furthermore, for a conservative benchmark of equal precision in public and private information, social welfare is higher than in a situation without public information. ${ }^{1}$

Angeletos and Pavan [3], Cornand and Heinemann [5], and Hellwig [7], have recently challenged the Morris and Shin result by extending Morris and Shin's model in different directions. ${ }^{2}$ In contrast, this paper challenges the Morris and Shin result in their original model.

In Morris and Shin's [8] elegant model, there is a continuum of economic agents indexed by the unit interval, $[0,1]$. Agent $i \in[0,1]$ chooses an action $a_{i} \in \mathrm{R}^{3}{ }^{3}$ Let $a$ denote the action profile over all agents. Agent $i$ has the utility function

$$
u_{i}(a, \theta) \equiv-\left[(1-r)\left(a_{i}-\theta\right)^{2}+r\left(L_{i}-\bar{L}\right)\right],
$$

where $r \in(0,1)$ is a constant, $\theta$ is state variable representing the state of the economy (the "fundamentals"), $L_{i} \equiv \int_{0}^{1}\left(a_{j}-a_{i}\right)^{2} d j$, and $\bar{L} \equiv \int_{0}^{1} L_{j} d j$. The first term of (1) corresponds to a standard fundamentals-related utility component: it is higher the closer the action is to the state of the economy. The second term corresponds to a zero-sum coordination game of guessing other agents' actions, corresponding to Keynes's beauty-contest example. The constant $r$ is the weight each agent puts on the beauty contest; $1-r$ is the weight on the fundamentals-related utility component.

Realized social welfare, $W(a, \theta)$, is the average utility of the agents (normalized by $1-r$ ),

$$
W(a, \theta) \equiv \frac{1}{1-r} \int_{0}^{1} u_{i}(a, \theta) d i=-\int_{0}^{1}\left(a_{i}-\theta\right)^{2} d i .
$$

It depends only on the fundamentals-related utility component.

Each agent receives the same public signal of $\theta, y=\theta+\eta$, where $\eta$, the noise in the public signal, is normally distributed with mean zero and variance $\sigma_{\eta}^{2}$. The variance $\sigma_{\eta}^{2}$ is a measure of

${ }^{1}$ Blinder and Wyplosz [4] provide further discussion of transparency and the Morris-Shin result.

2 These authors show that more public information increases welfare when there is increasing returns to scale (Angeletos and Pavan) or monopolistic competition (Hellwig) or when the public information under certain conditions is not provided to all agents (Cornand and Heinemann).

${ }^{3} x \in[a, b]$ is equivalent to $a \leq x \leq b . x \in(a, b)$ is equivalent to $a<x<b$. 
the noise in the public signal. Each agent $i$ also receives an individual private signal, $x_{i}=\theta+\varepsilon_{i}$, where $\varepsilon_{i}$, the noise in the private signal, is normally distributed with mean zero and variance $\sigma_{\varepsilon}^{2}$ and is independent of $\eta$ and $\varepsilon_{j}(j \neq i)$. The variance $\sigma_{\varepsilon}^{2}$ is a measure of the noise in the private signal.

After each agent has received the signals, each agent chooses the action $a_{i}$ so as to maximize his/her utility. Morris and Shin show that the unique equilibrium action $a_{i}$ of agent $i$ satisfies

$$
a_{i}=\frac{\alpha y+(1-r) \beta x_{i}}{\alpha+(1-r) \beta}
$$

where $\alpha \equiv 1 / \sigma_{\pi}^{2}$ denotes the precision of public information, and $\beta \equiv 1 / \sigma_{\varepsilon}^{2}$ denotes the precision of private information. Because the public signal is common knowledge, in equilibrium each agent gives more weight to the public signal and less weight to the private signal than their respective precisions, as shown by the factor $1-r$ multiplying the precision of the private signal. ${ }^{4}$

Given (2) and (3), expected social welfare for a given $\theta, \mathrm{E}[W(a, \theta)]$, satisfies

$$
\mathrm{E}[W(a, \theta)]=-\frac{\alpha+\beta(1-r)^{2}}{[\alpha+\beta(1-r)]^{2}} \equiv V(\alpha) .
$$

In the rest of this comment, social welfare refers to expected social welfare, is denoted $V(\alpha)$, and will be examined as a function of $\alpha$ for given $\beta$ and $r$.

Transparency is here defined as the precision of the public signal, $\alpha$. That is, more transparency is identified with higher precision of (less noise in) the public signal. The effect of a marginal increase in transparency on social welfare is then given by the derivative of social welfare with respect to the precision of the public information,

$$
V^{\prime}(\alpha)=\frac{\alpha-f(r) \beta}{[\alpha+\beta(1-r)]^{3}},
$$

where $f(r) \equiv(2 r-1)(1-r)$. Morris and Shin's main result [8, p. 1529] then follows directly and can be summarized as: Social welfare is decreasing in transparency, $V^{\prime}(\alpha)<0$, if and only if the condition

$$
\frac{\alpha}{\beta}<f(r)
$$

is satisfied.

\footnotetext{
${ }^{4}$ The standard signal-extraction problem with two signals and independent noise results in the equilibrium action $a_{i}=\frac{\alpha y+\beta x_{i}}{\alpha+\beta}$.
} 
However, scrutiny of the necessary and sufficient condition (6) shows that, under reasonable assumptions, the condition is very likely to be violated. If the condition is violated, more transparency is good and not bad for social welfare in this model.

First, we note, as did Morris and Shin, that for condition (6) to hold, the weight $r$ must satisfy the condition $r \in\left(\frac{1}{2}, 1\right)$. Otherwise, if $r \in\left[0, \frac{1}{2}\right]$ or $r=1$, we have $f(r) \leq 0$, and condition (6) is always violated. Thus, each agent must give more (but not all) weight to the beauty contest than to the fundamentals-related utility component. If not, social welfare is increasing in transparency.

Second, we note that $f(r) \leq f\left(\frac{3}{4}\right)=\frac{1}{8}$. That is, $f(r)$ has a maximum equal to $\frac{1}{8}$ for $r=\frac{3}{4}$. Thus, even if condition $r \in\left(\frac{1}{2}, 1\right)$ holds, condition (6) is violated, if $\alpha / \beta \geq 1 / 8$.

Thus, whenever the precision of the public signal is greater than $\frac{1}{8}$ of the precision of the private signal, social welfare is increasing in transparency. In terms of the noise levels, whenever the amount of noise in the public signal is less than 8 times the amount of noise in the private signal, social welfare is increasing in transparency. Furthermore, that factor 8 is the minimum factor, which arises for $r$ precisely equal to $\frac{3}{4}$. For instance, if $r$ is not $\frac{3}{4}$ but $\frac{5}{8}$ or $\frac{7}{8}$, the factor is $10 \frac{2}{3}$ and social welfare is even more likely to be increasing in transparency.

The private and public signals above are signals of $\theta$, an aggregate state of the economy. Central banks allocate many more resources to collecting, processing, and analyzing data about the economy than any private agent. It therefore seems extremely unlikely that the amount of noise in centralbank information should be more than 8 times that in the private information of an individual agent. Indeed, Romer and Romer [10] have shown that Federal Reserve Board forecasts are more accurate than private-sector forecasts. Therefore, a rather conservative benchmark case is when the precisions of the public and private information are equal, $\alpha=\beta$, in which case condition (6) is violated by a wide margin. ${ }^{5}$

Figure 1 corresponds to figure 1 in Morris and Shin [8] and gives a visual impression of the regions of $\alpha$ and $\beta$ for which social welfare is increasing or decreasing in transparency. The steeply sloped dashed ray through the origin is the border between the regions. Social welfare is increasing in transparency in the large region between the dashed ray and the horizontal axis. It is decreasing in the narrow region between the dashed ray and the vertical axis. The dashed ray is plotted with a slope equal to its minimum, 8, which arises when $r=\frac{3}{4}$. For $r \neq \frac{3}{4}$, the slope of the ray is even steeper, the region of increasing social welfare is larger, and the region of decreasing social welfare

\footnotetext{
${ }^{5}$ In the realistic case that the relevant information concerns not only the state of the economy but the central bank's intentions, the precision of the central bank's information is even more likely to be higher than that of the private information of an individual agent.
} 


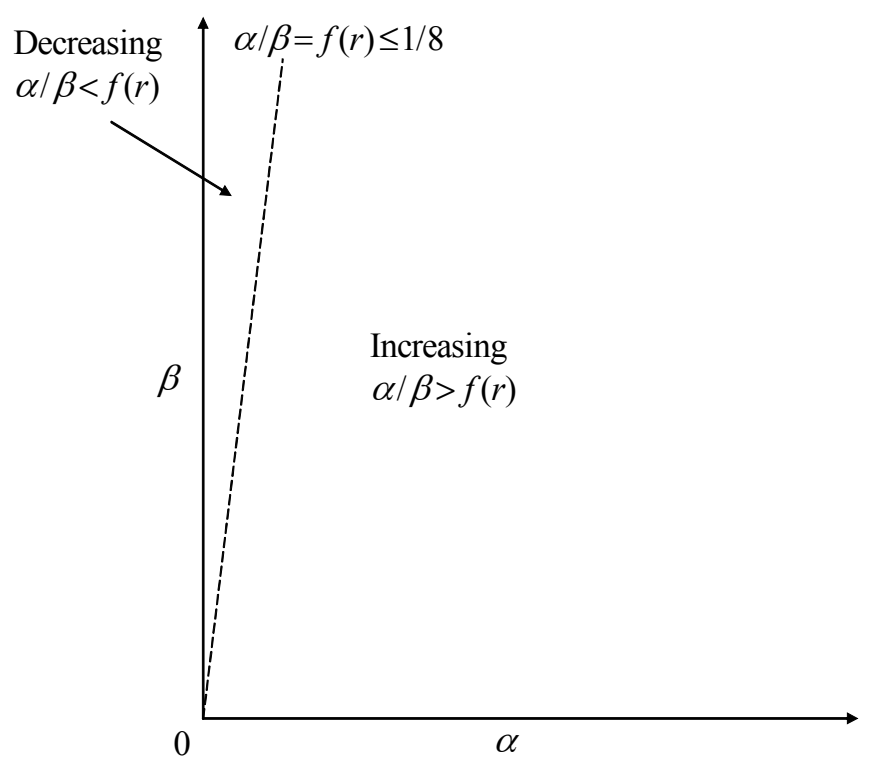

Figure 1: Regions of social welfare increasing or decreasing in transparency

is smaller. The slope of the ray in Morris and Shin's figure 1 is misleadingly flat (in the default case when the scales of the two axes are the same).

The conservative benchmark of equal precision of the public and private signals, $\alpha=\beta$, corresponds in figure 1 to a 45-degree ray from the origin. This ray is inside the region of increasing social welfare, by a wide margin.

In figure 2, the solid curve shows social welfare as a function of transparency. More precisely, social welfare (scaled by $\beta$ and for convenience shifted up by 1.5) is plotted against the ratio $\alpha / \beta$ (alternatively, we can for simplicity consider $\beta$ held fixed at unity). The weight $r$ is set equal to $r=\frac{3}{4}$, so the region of social welfare decreasing in transparency is maximized. Social welfare is decreasing in transparency for $\alpha / \beta<1 / 8$, has a minimum for $\alpha / \beta=1 / 8$, and is increasing for $\alpha / \beta>1 / 8$. The dashed curve shows the derivative of social welfare (scaled by $\beta^{2}$ ) with respect to $\alpha$-that is, the marginal social benefit of transparency-plotted against $\alpha / \beta$. The marginal social benefit of transparency is negative for $\alpha / \beta<1 / 8$, zero for $\alpha / \beta=1 / 8$, and positive for $\alpha / \beta>1 / 8$. If the weight $r$ satisfies $r \in\left(\frac{1}{2}, 1\right)$ but is different from $\frac{3}{4}$, the minimum of the social welfare occurs for $\alpha / \beta<1 / 8$ and the region of decreasing social welfare is even smaller. The conservative benchmark of equal precision of the public and private signals, $\alpha / \beta=1$, well into the region of increasing welfare.

The above discussion refers to marginal changes in transparency. We may also want to consider 


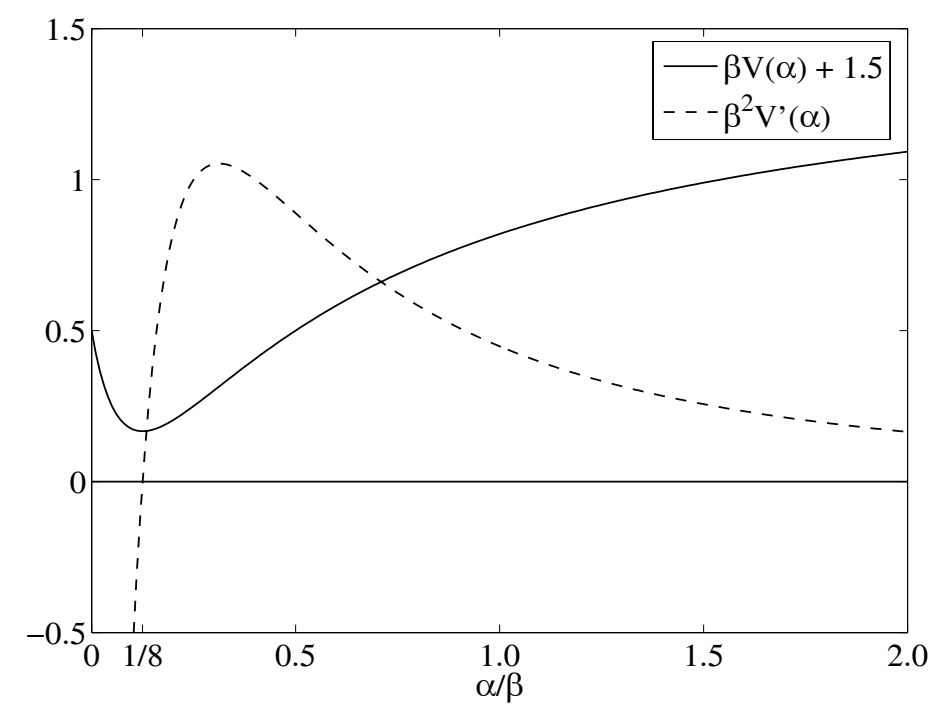

Figure 2: Social welfare as a function of transparency

non-marginal changes in transparency. We see in figure 2 that social welfare has a local maximum for $\alpha=0$. Therefore, we may want to ask how large $\alpha$ must be in order to bring higher social welfare than $\alpha=0$. In particular, for the conservative benchmark of equal precision of the public and private signals, is social welfare higher than for $\alpha=0$ ?

By (4), we have $V(0)=-1 / \beta$. We also see that a global maximum of social welfare occurs for maximum transparency, infinite precision of the public signal, $\lim _{\alpha \rightarrow \infty} V(\alpha)=0$. We would like to find the threshold $\bar{\alpha}>0$ for which $V(\bar{\alpha})=-1 / \beta$. Simple algebra gives

$$
\bar{\alpha}=\beta(2 r-1)<\beta,
$$

where the inequality follows from $r<1$. Hence, for $\alpha>\bar{\alpha}$, we have $V(\alpha)>V(0)$. Furthermore, since $r<1$, we have $\bar{a}<\beta$. Therefore, for our conservative benchmark of equal precision of the public and private signals, social welfare is higher than for $\alpha=0$. In figure 2 , where $r=\frac{3}{4}$, we have $\bar{\alpha} / \beta=\frac{1}{2}$, so for $\alpha / \beta>\frac{1}{2}$, social welfare is higher than for $\alpha=0$.

However, note that $\alpha=0$ corresponds to a the hypothetical situation of no public information. In any realistic situation in which changes in central-bank transparency is considered, there is always some public information, corresponding to $\alpha>0$, away from the local maximum at $\alpha=0$. It is never feasible to eliminate all public information. Thus, a realistic case of minimum transparency with a positive $\alpha$ entails lower social welfare than $\alpha=0$, making the corresponding threshold $\bar{\alpha}$ even lower than the one in (7). Furthermore, the minimum level of public information might even be above the small level $\beta f(r)$ at which social welfare becomes increasing in transparency, making 
social welfare always increasing in transparency. ${ }^{6}$

In summary, the obvious conclusion is that, for reasonable parameters, social welfare is increasing in transparency in the Morris and Shin model. Furthermore, a conservative benchmark of equal precision of the public and private signals leads to higher social welfare than when there is no public information. The Morris-Shin result has been largely misinterpreted as an anti-transparency result, but it is actually pro transparency. ${ }^{7}$

\footnotetext{
${ }^{6}$ The above analysis is easily extended to the case when the level of transparency is subject to choice and increasingly costly to achieve. With a positive marginal cost of increasing transparency, at an optimal level of transparency, social welfare will always be increasing in transparency (if social welfare net of the cost exceeds social welfare net of the cost at the minimum level of transparency).

7 Morris, Shin, and Tong [9] provide discussion of a more elaborate example, with correlated private and public signals. The private signal is $x_{i}=\theta+\frac{1}{2} z+\frac{1}{2} \varepsilon_{i}$, and the central bank receives two signals, $\theta+\omega z$ and $\theta+\varepsilon_{c}$, where $z, \varepsilon_{i}$, and $\varepsilon_{c}$ are normal and iid with zero means and unit variances. For this example, $\omega=\frac{1}{2}$ would seem to be a sensible benchmark case (for instance, if the central bank collects and averages the private signals). Then, the central bank disclosing its best estimate of $\theta, y_{1}=\theta+\frac{1}{1+\omega^{2}} \omega z+\frac{\omega^{2}}{1+\omega^{2}} \varepsilon_{c}$, increases social welfare, even though the signals are correlated.
} 


\section{References}

[1] Amato, Jefferey D., Stephen Morris, and Hyun Song Shin (2002), "Communication and Monetary Policy," Oxford Review of Economic Policy 18, 495-503.

[2] Amato, Jefferey D., and Hyun Song Shin (2003), "Public and Private Information in Monetary Policy Models," BIS Working Paper No. 138, www.bis.org.

[3] Angeletos, George-Marios, and Alessandro Pavan (2004), "Transparency of Information and Coordination in Economies with Investment Complementarities," working paper.

[4] Blinder, Alan S., and Charles Wyplosz (2004), "Central Bank Talk: Committee Structure and Communication Policy," working paper, prepared for the ASSA meeting, Philadelphia, January 7-9, 2005.

[5] Cornand, Camille, and Frank Heinemann (2004), "Optimal Degree of Public Information Dissemination," working paper, www.sfm.vwl.uni-muenchen.de/heinemann/home.html.

[6] Economist (2004), "It's Not Always Good to Talk," 22 July 2004, 71.

[7] Hellwig, Christian (2004), "Heterogenous Information and the Benefits of Transparency," working paper, www.econ.ucla.edu/people/faculty/Hellwig.html.

[8] Morris, Stephen, and Hyun Song Shin (2002), "The Social Value of Public Information," American Economic Review 92, 1521-1534.

[9] Morris, Stephen, Hyun Song Shin, and Hui Tong (2005), "Response to 'The Social Value of Public Information: Morris and Shin (2002) is Actually Pro Transparency, Not Con', American Economic Review, forthcoming.

[10] Romer, Christina D., and David H. Romer (2000), "Federal Reserve Private Information and the Behavior of Interest Rates," American Economic Review 90, 429-457.

[11] Svensson, Lars E.O. (2003), "Comment on Amato, Jefferey D., and Hyun Song Shin, 'Public and Private Information in Monetary Policy Models'," presented at the conference "Monetary Stability, Financial Stability and the Business Cycle," Bank for International Settlements, Basel, March 28-29, 2003, www.princeton.edu/ svensson. 